\title{
Clinical utility of dental cone-beam computed tomography: current perspectives
}

This article was published in the following Dove Press journal:

Clinical, Cosmetic and Investigational Dentistry

2 April 2014

Number of times this article has been viewed

\author{
Prashant P Jaju' \\ Sushma P Jaju² \\ 'Oral Medicine and Radiology, \\ ${ }^{2}$ Conservative Dentistry and \\ Endodontics, Rishiraj College of \\ Dental Sciences and Research \\ Center, Bhopal, India
}

Correspondence: Prashant P Jaju Department of Oral Medicine and Radiology, Rishiraj College of Dental Sciences and Research Center, Bhopal, 462003, India Tel +9l 975209301 I

Email docprashant_jaju@yahoo.com

\begin{abstract}
Panoramic radiography and computed tomography were the pillars of maxillofacial diagnosis. With the advent of cone-beam computed tomography, dental practice has seen a paradigm shift. This review article highlights the potential applications of cone-beam computed tomography in the fields of dental implantology and forensic dentistry, and its limitations in maxillofacial diagnosis.
\end{abstract}

Keywords: dental implants, cone-beam computed tomography, panoramic radiography, computed tomography

\section{Introduction}

Cone-beam computed tomography (CBCT) is a new diagnostic tool that has revolutionized diagnosis and treatment planning in the dental field. CBCT presents as a separate $\mathrm{C}$-arm to computed tomography (CT) imaging. An early volumetric $\mathrm{CT}$ predecessor of CBCT, the dynamic spatial reconstructor, was developed in the late 1970s by the Biodynamics Research Unit at the Mayo Clinic (Rochester, MN, USA). ${ }^{1}$ Initial interest has focused primarily on applications in angiography in which softtissue resolution could be sacrificed in favor of high temporal- and spatial-resolving capabilities. ${ }^{1}$ CBCT provided an alternate method of cross-section image production to fan-beam CT using a comparatively less expensive radiation detector than conventional CT. The technology transfer of CBCT to dentistry first occurred in 1995. Italian coinventors, Tacconi and Mozzo, developed a CBCT system for the maxillofacial region that was designed and produced by QR Srl of Verona, Italy. ${ }^{1}$ This unit, the NewTom QR-DVT 9000, became the first commercial CBCT unit marketed specifically to the dental market, and it was initially introduced in Europe in 1999. ${ }^{1}$ Currently, numerous manufacturers have introduced CBCT machines in different fields of view (FOVs), as per clinical practice requirements (Table 1).

CBCT was initially introduced for its indispensable role in the field of dental implantology. ${ }^{1}$ Currently, the utility of CBCT encompasses field of dental implantology, oral surgery, orthodontics, endodontics, sleep apnea, temporomandibular joint (TMJ) disorders, and periodontics, and it is expanding its horizon in the field of ear, nose, and throat (ENT) medicine. ${ }^{2,3}$

\section{CBCT in dental implantology}

Dental implants are considered to be a boon to edentulous patients, thereby improving their overall health and longevity. ${ }^{1} \mathrm{CBCT}$ has revolutionized the way dental implant 
Table I List of CBCT machines depending upon their FOV

\begin{tabular}{|c|c|c|c|}
\hline $\begin{array}{l}\text { Field of view } \\
\text { (FOV) }\end{array}$ & CBCT machine & Manufacturer & $\begin{array}{l}\text { Maximum FOV }(\mathrm{cm}) \\
\text { (height*width) }\end{array}$ \\
\hline \multirow[t]{5}{*}{$\begin{array}{l}\text { Large }\left(\mathrm{FOV}_{1}\right) \\
>15 \mathrm{~cm}\end{array}$} & $\mathrm{i}-\mathrm{CA} \mathrm{T}^{\circledR}$ & $\begin{array}{l}\text { Imaging Sciences International Inc. (Hatfield, } \\
\text { PA, USA) }\end{array}$ & $17 * 23$ \\
\hline & CB MercuRay & $\begin{array}{l}\text { Hitachi Medical Systems America Inc. } \\
\text { (Twinsburg, OH, USA) }\end{array}$ & $20 * 20$ \\
\hline & NewTom 3G & QR Srl (Verona, Italy) & $20 * 20$ \\
\hline & KODAK 9500 & Carestream Health (Rochester, NY, USA) & $|8 * 2|$ \\
\hline & ProMax $^{\circledast}$ 3D Max & Planmeca OY (Helsinki, Finland) & $16 * 23$ \\
\hline Medium $\left(\mathrm{FOV}_{M}\right)$ & GALILEOS & Sirona Dental GmbH (Salzburg, Austria) & $15 * 15$ \\
\hline \multirow[t]{4}{*}{$10-15 \mathrm{~cm}$} & KODAK CS 9300 & Carestream Health & $13.5 * 17$ \\
\hline & SCANORA $^{\otimes} 3 \mathrm{D}$ & Soredex (Milwaukee, WI, USA) & $7.5 * 14.5$ \\
\hline & NewTom VGi & QR Srl & $15 * 15$ \\
\hline & ProMax $^{\circledR}$ 3D Mid & Planmeca OY & $9 * 16$ \\
\hline Small $\left(\mathrm{FOV}_{\mathrm{s}}\right)$ & ORTHOPHOS XG 3D & Sirona Dental GmbH & $8 * 8$ \\
\hline \multirow[t]{4}{*}{$<10 \mathrm{~cm}$} & KODAK 9000 3DC & Carestream Health & $4 * 5$ \\
\hline & GXDP-7000TM & Gendex Dental Systems (Hatfield, PA, USA) & $6 * 8$ \\
\hline & ProMax $^{\circledast} 3 \mathrm{D}$ & Planmeca OY & $8 * 8$ \\
\hline & 3D Accuitomo 80 & J Morita USA, Inc. (Irvine, CA, USA) & $8 * 8$ \\
\hline
\end{tabular}

Abbreviations: $\mathrm{CBCT}$, cone-beam computed tomography; FOV, field of view.

practice is performed in dental clinics and hospitals. Past decades have shown a paradigm shift from a surgically-driven to a prosthetically-driven approach in dental implant therapy. ${ }^{3}$ To improve the overall success of implant therapy with possible reduction in surgical and postoperative implant complications, implantologists should have three-dimensional (3D) information of bone volume and topography prior to implant placement. ${ }^{4}$ Presurgical assessment of implant site by imaging technique thus allows for the accurate assessment of the amount of bone volume available, bone density, and proximity to anatomical structures (Table 2).

$\mathrm{CBCT}$ is the preferred option for implant dentistry as it provides greater measurement accuracy when compared to two-dimensional (2D) imaging, while utilizing lower doses of radiation..$^{5-8}$ Loubele et $\mathrm{al}^{9}$ reported that both $\mathrm{CBCT}$ and
CT yielded submillimeter accuracy for linear measurements on an ex vivo specimen for implant measurements.

\section{Ridge morphology}

The buccolingual ridge pattern cannot be viewed on 2D radiographs, but $\mathrm{CBCT}$ provides the advantage of showing the type of alveolar ridge pattern present. ${ }^{10}$ Cross-sectional images provide the implantologist with the appearance of ridge patterns, such as irregular ridge, narrow crestal ridge, and knife shape ridge. Also, the loss of cortical plates and undulating concavities can also be appreciated on crosssectional images, and they cannot be seen on panoramic images. Mcginvney et al and Schwartz et al concluded that $3 \mathrm{D}$ images more accurately reflected true osseous topography, and they considered it a valuable diagnostic aid. ${ }^{10}$ In the

Table 2 Comparison of imaging modalities in the field of dental implantology

\begin{tabular}{|c|c|c|c|c|c|c|}
\hline Imaging goal & Cephalometric & Periapical & OPG & Tomography & CT & CBCT \\
\hline Bone height & I & 3 & 2 & 3 & 4 & 4 \\
\hline Bone width & 0 & 0 & 0 & 3 & 4 & 4 \\
\hline Long axis or ridge & 0 & 0 & 0 & 3 & 4 & 4 \\
\hline Anatomy localization & 1 & I & I & 3 & 4 & 4 \\
\hline Bone quality & 0 & 2 & 2 & 2 & 4 & 3 \\
\hline Pathology identification & I & 2 & 3 & 2 & 3 & 4 \\
\hline Jaw boundary identification & I & 0 & 2 & 3 & 4 & 4 \\
\hline Virtual planning & 0 & 0 & I & I & 4 & 4 \\
\hline Guide fabrication & 0 & 0 & 0 & 0 & 4 & 4 \\
\hline Communication aid & 2 & 1 & 2 & 2 & 4 & 4 \\
\hline Benefit/risk/cost ratio & I & I & 2 & 2 & 3 & 4 \\
\hline
\end{tabular}

Notes: Ranking score: $0=$ no score; $I=$ low value; $2=$ mild value; $3=$ moderate value; $4=$ high value. (Scoring type based on its performance divided into no; low; mild; moderate; high).

Abbreviations: OPG, orthopantogram; CT, computed tomography; CBCT, cone-beam computed tomography. 
case of a compromised jaw bone (in terms of quality and/or quantity of bone), the panoramic technique is an inefficient imaging tool. In case of potential risks in treatment plan $3 \mathrm{D}$ imaging may prove indispensable. ${ }^{10}$

\section{Quality of bone at implant sites}

The term "bone quality" is commonly used in implant treatment and in reports on implant success and failure. ${ }^{11}$ Lindh et $\mathrm{al}^{11}$ emphasized that bone density (bone mineral density) and bone quality are not synonymous. Bone quality encompasses factors other than bone density such as skeletal size, bone architecture, the $3 \mathrm{D}$ orientation of the trabecula, and matrix properties. Bone quality is not only a matter of mineral content, but also of structure. It has been shown that the quality and quantity of bone available at the implant site are very important local patient factors in determining the success of dental implants. ${ }^{12}$ Bone quality is categorized into four groups: groups 1-4 or types 1-4 (Bone Quality Index): ${ }^{13}$

- Type 1: homogeneous cortical bone;

- Type 2: thick cortical bone with marrow cavity;

- Type 3: thin cortical bone with dense trabecular bone of good strength; and

- Type 4: very thin cortical bone with low density trabecular bone of poor strength.

In the jaws, an implant placed in poor-quality bone with thin cortex and low-density trabeculae (Type 4 bone) has a higher chance of failure compared with the other types of bones. ${ }^{11}$ This low-density bone is often found in the posterior maxilla, and several studies report higher implant failure rates in this region. ${ }^{10}$

Bone density can be obtained from CT units and expressed in terms of Hounsfield units (HU). The HU is not part of the system international (SI) system. In fact, it is a practical unit that represents the relative deviation of the measured linear attenuation of a material from that of water. X-ray beams used for diagnostic radiology are not monochromatic and, hence, are composed of photons with a broad spectrum of energies. ${ }^{14}$ This is the fundamental reason why the HU value for tissues obtained from one CT system may not be the same as that obtained using a different CT system, or even with the same machine, if different technique-related factors are used. ${ }^{14}$

Unlike CT units, current CBCT units do not use a standard scaling system. Methods have been proposed to convert CT numbers measured on CBCT scans to HU. However, such methods make the implicit assumption that the relationship between CT numbers and X-ray attenuation is uniform throughout the volume of the CBCT image. ${ }^{14}$ Several factors like beam hardening, artifacts from metallic restorations, and scattered radiation contribute to the heterogeneity of CT numbers on CBCT scans. Our experience shows us that even the same anatomic region on CBCT scans may not demonstrate the same CT numbers. In general, smaller irradiated and reconstructed volumes (small FOVs) are less prone to inaccurate CT numbers caused by scattered radiation and nonideal geometry; therefore, whenever there is no need for large volume coverage, a small FOV should be used instead of a large FOV. ${ }^{14}$

In order for HUs on CBCT to be used with confidence, the accuracy of the HU should be known, so that the clinician can assess whether or not the HUs can be used for specific clinical tasks. ${ }^{14}$ With more advanced CBCT software and methods, it should be possible to improve the accuracy of CBCT HU values when determining bone densities at implant sites. Thus, it can be concluded that CBCT provides a subjective assessment of bone quality, and not objective assessment.

\section{CBCT-guided implant surgery}

Type and size of the planned implant, its position within the bone, its relationship to the planned restoration and adjacent teeth and/or implants, and its proximity to vital structures can be determined before performing surgery (Figure 1). This is possible with the integration of CBCT scans with computeraided design/computer-aided manufacturing technology (for example, CEREC; Sirona Dental GmbH, Salzburg, Austria). Computer-generated surgical guides can be fabricated from the virtual treatment plan. These surgical guides are used by the implantologist to place the planned implants in the patient's mouth in the same position as in the virtual treatment plan, allowing for more accurate and predictable implant placement and reduced patient morbidity. ${ }^{15}$ Surgical guides are not indicated for every case; indications are as follows:

- Three or more implants in a row

- Proximity to vital anatomic structures

- Problems related to the proximity of adjacent teeth

- Questionable bone volume

- Implant position that is critical to the planned restoration

- Flapless implant placement

- Multiple unit or immediate full-arch restorations, with or without extractions, and immediate placement.

Conventional surgical stents that aid in implant positioning have been used in implant dentistry for many years. Guides are fabricated from vacuform shells with the buccal or palatal/lingual facings of the planned restorations, or they may be more complex with $2 \mathrm{~mm}$ drill holes or metal tubes (Figure 2). There is a lack of a correlation in these appliances between the planned restoration and the underlying 


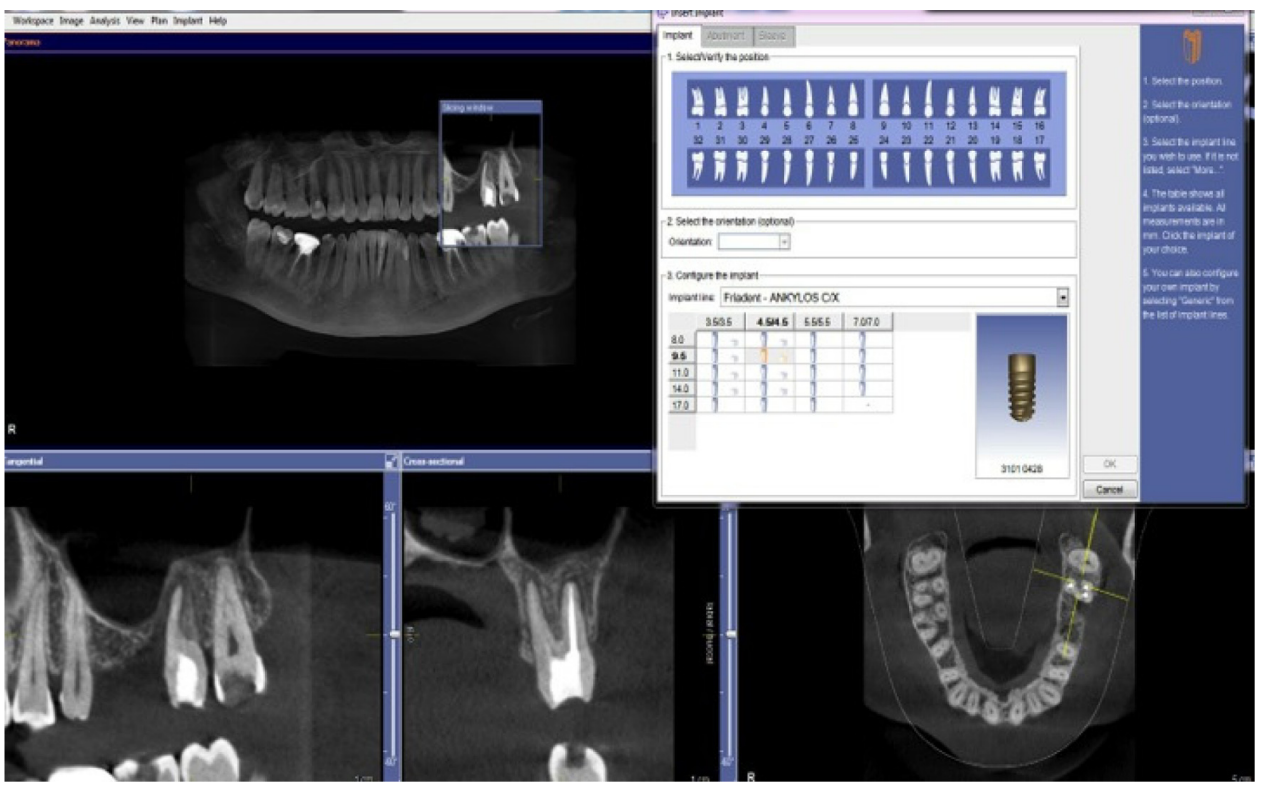

Figure I Virtual implant planning by selecting the desired implant from an implant library.

bony anatomy. With the use of computer-guided implant surgical guides, this anatomic relationship can be predictably established and considered before surgery. ${ }^{15}$ Gutta-percha, barium sulfate, and lead foils have been traditionally used for the fabrication of surgical guides; bone and soft tissue loss from periodontal disease, as well as atrophy, long-term denture wear, and sinus pneumatization can make it difficult to predictably use traditional surgical guides. ${ }^{15}$

Three types of computer-generated surgical guides are currently available: ${ }^{15}$

1. Tooth supported;

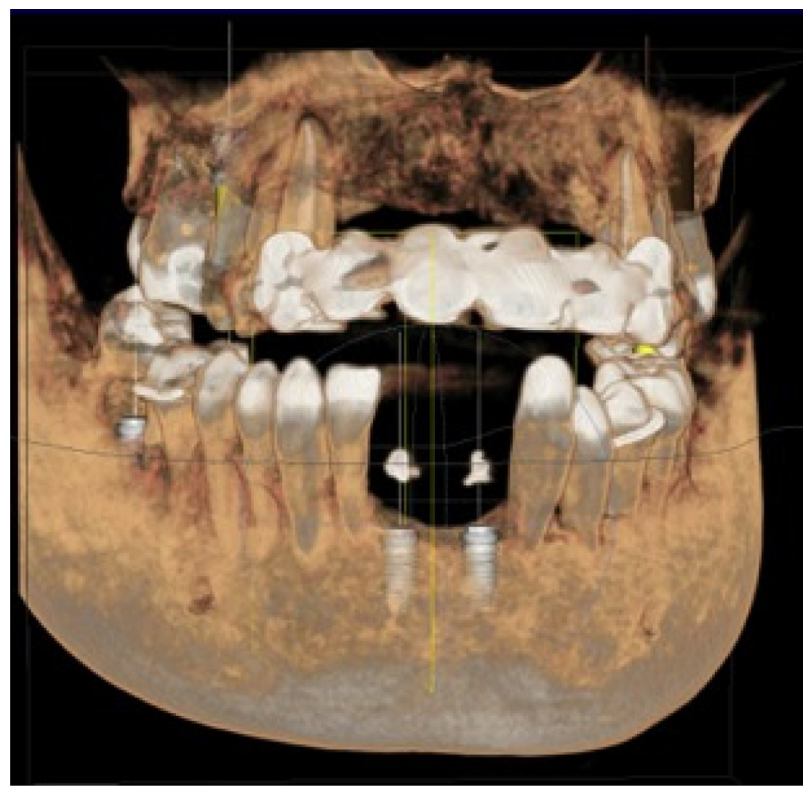

Figure 2 Gutta percha used as a radiographic template.
2. mucosa supported; and

3. bone supported.

Tooth supported guides are used in partially edentulous cases. This surgical guide is designed to rest on other teeth in the arch for accuracy of guide fit. Mucosal supported guides are used primarily in fully edentulous cases and are designed to rest on the mucosa. Accurate interarch bite registrations are of the utmost importance when using these guides to assure accurate surgical guide positioning and placement of securing screws/pins before the placement of implants. Bone supported guides can be used in partially or fully edentulous cases, but they are primarily used in fully edentulous cases in which significant ridge atrophy is present and good seating of a mucosa supported guides is questionable. ${ }^{15}$ Currently, only SimPlant ${ }^{\circledR}$ (Materialise Dental, Leuven, Belgium) manufactures bone supporting surgical guides. ${ }^{15}$

Radiation doses delivered to the patient by CBCT need to be evaluated properly. It has been reported that in implant imaging, CT delivers the highest radiation dose to the salivary glands, whereas the CBCT system studied delivered the lowest dose. ${ }^{16}$

\section{Recommendations by American Academy of Oral and Maxillofacial Radiology (AAOMR) for role of CBCT in dental implantology}

The following are recommendations for the role of $\mathrm{CBCT}$ in dental implantology, as made by the AAOMR: ${ }^{4}$ 
- Recommendation 1: panoramic radiography should be used as the imaging modality of choice in the initial evaluation of the dental implant patient.

- Recommendation 2: use intraoral periapical radiography to supplement the preliminary information from panoramic radiography.

- Recommendation 3: do not use cross-sectional imaging, including $\mathrm{CBCT}$, as an initial diagnostic imaging examination.

- Recommendation 4: the radiographic examination of any potential implant site should include cross-sectional imaging orthogonal to the site of interest.

- Recommendation 5: CBCT should be considered as the imaging modality of choice for preoperative crosssectional imaging of potential implant sites.

- Recommendation 6: CBCT should be considered when clinical conditions indicate a need for augmentation procedures or site development before the placement of dental implants: 1) sinus augmentation; 2) block or particulate bone grafting; 3) ramus or symphysis grafting; 4) assessment of impacted teeth in the field of interest; and 5) evaluation of prior traumatic injury.

- Recommendation 7: CBCT imaging should be considered if bone reconstruction and augmentation procedures (for example, ridge preservation or bone grafting) have been performed to treat bone volume deficiencies before implant placement.

- Recommendation 8: in the absence of clinical signs or symptoms, use intraoral periapical radiography for the postoperative assessment of implants. Panoramic radiographs may be indicated for more extensive implant therapy cases.

- Recommendation 9: use cross-sectional imaging (particularly CBCT) immediately postoperatively, only if the patient presents with implant mobility or altered sensation, especially if the fixture is in the posterior mandible.

- Recommendation 10: do not use CBCT imaging for the periodic review of clinically asymptomatic implants.

- Recommendation 11: cross-sectional imaging, optimally CBCT, should be considered if implant retrieval is anticipated.

\section{CBCT in oral and maxillofacial surgery}

A combination of low radiation dose, high-quality bony definition, and compact design requiring minimum space has made CBCT desirable as an in-office imaging system for the examination of pathologies in the head and neck, extracranial, paranasal, and temporal bone regions. ${ }^{17,18}$

\section{Third molar evaluation}

Dental clinics are routinely visited by young adults for the removal of third molars. ${ }^{19}$ Damage to the inferior alveolar nerve (IAN) is a serious complication following third molar removal. The overall risk of temporary IAN injury associated with third molar removal ranges from $0.4 \%-6 \%{ }^{20}$ It is important to preoperatively assess the position, and establish the relationship, of the third molar with the mandibular canal to minimize the risk of nerve injury. ${ }^{19}$ Clinicians use various radiographic markers to indicate a close relationship between the third molar and the mandibular canal. ${ }^{20}$ Panoramic and intraoral radiographs are sufficient for preoperative imaging in most cases where there is no overlap between the IAN and the lower third molar. ${ }^{19}$ Where there are radiographic signs of an overlapping impacted tooth with the mandibular canal, panoramic radiographs provide limited information. The buccolingual relationship between the IAN and the lower third molar cannot be evaluated from panoramic radiographs. Furthermore, the presence or absence of cortication around the IAN and the detailed anatomy of the third molar may not be clearly evident with this method. ${ }^{20}$

In their study, Kamrun et $\mathrm{al}^{21}$ revealed that the visibility of the superior border on panoramic images was very poor, except for the most posterior area, which clearly confirmed the limitations of panoramic radiography. The poor visualization of the canal on panoramic images was considered to be remarkably improved by the use of CBCT. ${ }^{21}$

Several studies have shown that panoramic radiography has only limited accuracy in determining the number of roots and in describing root morphology. ${ }^{19} \mathrm{CBCT}$ proved to be more reliable in determining the number of roots than did panoramic radiography. ${ }^{19}$ Tantanapornkul et $\mathrm{al}^{22}$ concluded that the 3D X-Ray CBCT (J Morita USA, Inc., Irvine, CA, USA) was significantly more accurate when compared with panoramic radiography in predicting IAN exposure during third molar removal with a sensitivity of $93 \%$ and a specificity of $77 \% .^{22}$ The patient can also be more adequately informed about his or her risk profile. Almost all of the CBCT software provided by manufacturers, as well as third-party software, has a nerve tracing application. This allows for the identification and color coding of the mandibular nerve, thereby assisting in easy recognition (Figure 3).

The maxillary permanent canine has a crucial esthetic and functional value, but it is the second most frequently impacted tooth following the third molar. ${ }^{23,24}$ The prevalence of maxillary permanent canine impaction is about $1 \%-3 \%{ }^{25}$ The decision for interceptive treatment takes into account several factors, including how to expose, recover, extract, or not treat. ${ }^{19,20}$ Some factors include location of the impaction, 


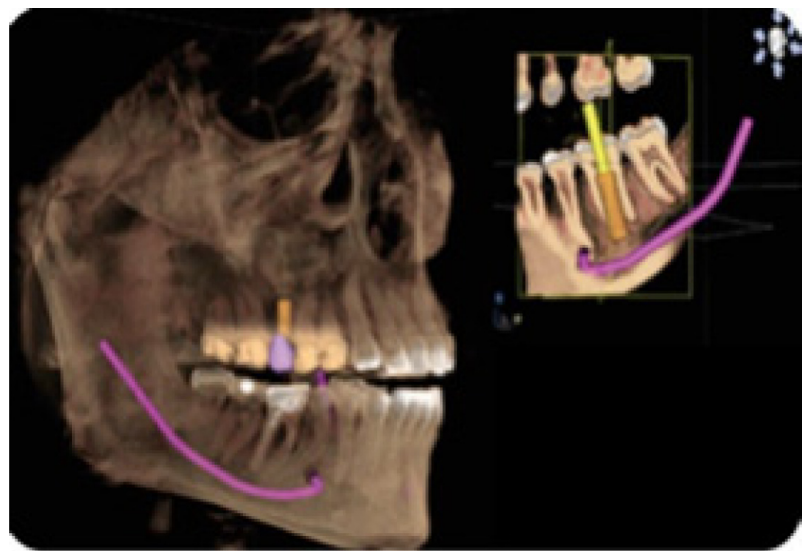

Figure 3 Color coding of the mandibular nerve on Sirona software (Sirona Dental $\mathrm{GmbH}$, Salzburg, Austria).

prognosis of intervention on the impacted tooth and adjacent teeth, surgical accessibility, impact of treatment on the final functional occlusion, and possible surgical morbidity. ${ }^{19,20}$ Even though maxillary canine tooth buds develop labially to adjacent tooth roots, the ratio of palatal impactions to labial impactions is at least $3: 1 .^{26}$ As expected, most impacted teeth can be accurately localized with traditional radiographs. However, this is not true for every impacted canine; some can be incorrectly localized, poorly accessed surgically, or they can be recovered by using deleterious vectors (Figure 4). Ericson and $\mathrm{Kurol}^{27}$ demonstrated that $8 \%$ of impacted maxillary canines could not be accurately localized in the labio-palatal dimension with periapical radiographs. CBCT with its 3D orientation can precisely locate the position of the impacted canine and thus assist the oral surgeon in planning the treatment. ${ }^{28}$ According to study done by Alqerban et al, ${ }^{29}$ surgical treatment planning of impacted maxillary canines was not significantly different between panoramic and CBCT images.

\section{Bony pathology assessments}

Oral maxillofacial pathologies are routinely encountered by clinicians; demographic data, clinical complaints, and examination of the oral cavity are performed. ${ }^{3}$ After thorough clinical examination, radiological and laboratory investigations are warranted to gather at a presumptive diagnosis. The exposed images are examined to look for the lesion's exact location (maxilla, mandible, anterior, posterior, alveolar process, and so forth). The exact size of the defect and its relative density (radiolucent or radiopaque, or a combination of the two) are determined..$^{30} \mathrm{CBCT}$ is recommended when there is a need to diagnose a cyst, tumor, or infections in the alveolar process and jaw bone (Figure 5). ${ }^{31}$
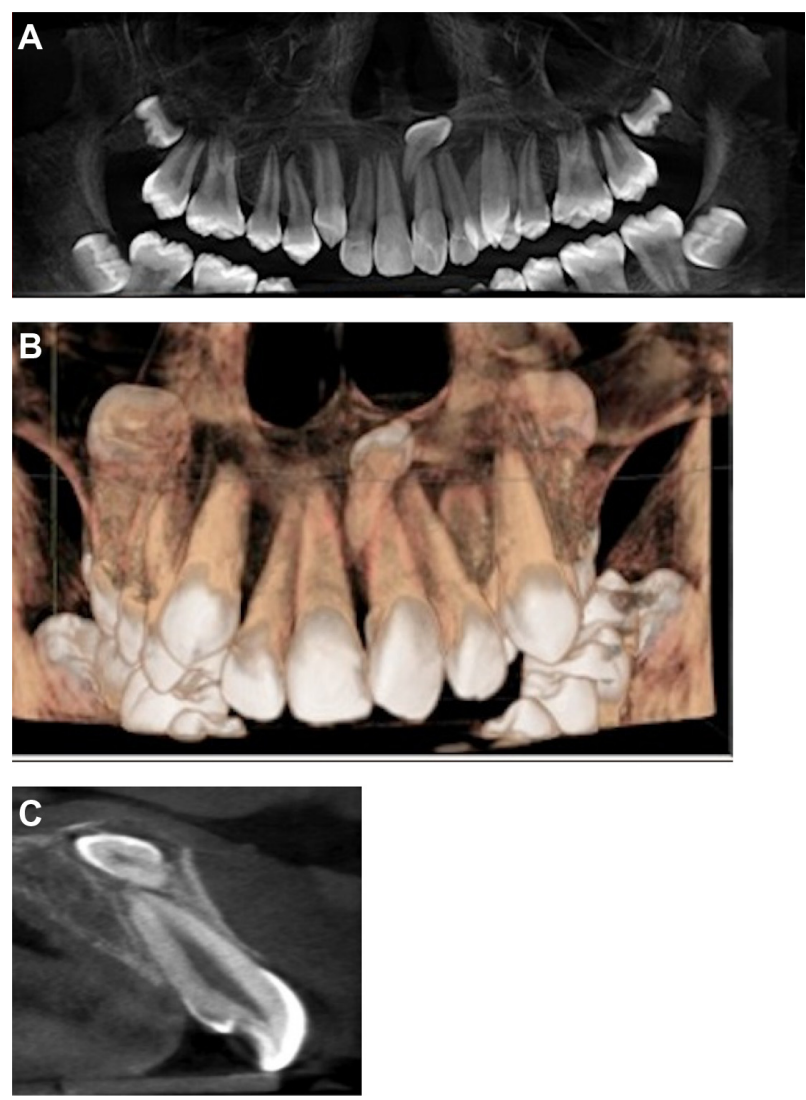

Figure $4 \mathrm{CBCT}$ images (panoramic/3D reconstruction/cross-sectional) eases treatment planning for impacted mesiodens.

Notes: (A) Panoramic radiograph showing mesiodens. (B) 3D reconstruction showing impacted mesiodens. (C) Cross sectional view showing relation of impacted mesiodens with central incisor.

Rare calcifying lesions, such as a calcifying cystic odontogenic tumor, can be examined in CBCT images for their particular variations. CBCT has proven its worth in the evaluation of intraosseous lesions that are in close proximity to vital organs and vasculature in the head and neck region. ${ }^{31}$ Although the reliability of CBCT in detecting the invasion
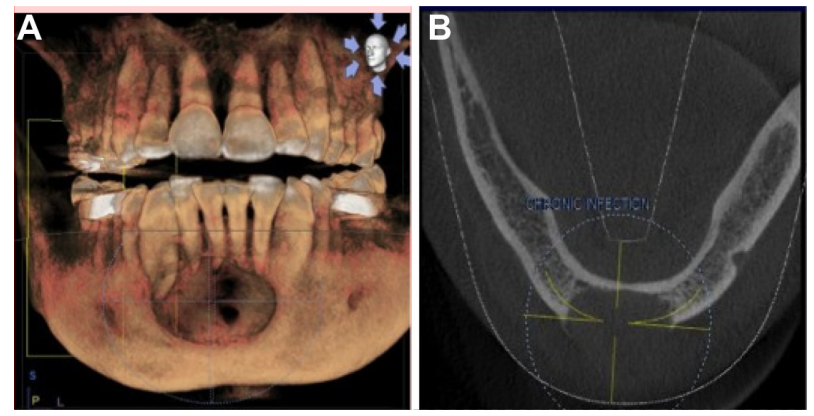

Figure 5 Large radiolucent lesion in the anterior mandible with perforation of the labial cortical plates, as seen on CBCT.

Notes: (A) 3D reconstruction showing extensive radiolucent lesion in anterior mandible. (B) Loss of buccal cortical plate clearly demonstrated on axial view. Abbreviation: $\mathrm{CBCT}$, cone-beam computed tomography. 
or erosion of oral malignancy such as oral squamous cell carcinoma is still under investigation, a study has suggested that the combination of dynamic contrast-enhanced magnetic resonance imaging (MRI) and CBCT may be a useful tool in delineating tumor boundaries and in developing appropriate surgical interventions. ${ }^{32}$

In their study, Dreiseidler et $\mathrm{al}^{33}$ showed a slightly superior overall diagnostic reliability for the assessment of a malignancy's bone infiltration to CBCT compared with CT and single-photon emission CT. They concluded that the FOV-to-radiation dose ratio, easy panoramic view reconstruction, and clinical accessibility were responsible for the better performance of CBCT in diagnosis over multislice CT (MSCT) for the preoperative maxillofacial assessment of tumor invasion into the bone. ${ }^{33} \mathrm{CBCT}$ can also be teamed with stereolithographic model construction, which can be used in conjunction with dental implant placement or in the reconstruction of jaws resected due to pathology. ${ }^{30}$

\section{Maxillofacial trauma}

Dentoalveolar fracture, maxillary bone fracture, zygomatic complex fracture, mandibular fracture, or gunshot injuries require radiographs for precise location of the fracture. Panoramic radiographs and numerous extra oral radiographs are routinely used in maxillofacial trauma cases. ${ }^{34}$ Authors recommend the use of CBCT when compared with panoramic radiograph in identifying the location of a cortical plate fracture that is not complete. ${ }^{34}$ Additionally, CBCT is more sensitive and accurate in imaging the maxilla and mandible. It is reported that mandibular fractures that are not evident in conventional CT can be identified using CBCT. Also, when using $\mathrm{CBCT}$, as compared to $\mathrm{CT}$ and conventional radiograph, information about dentoalveolar fractures is more detailed. This makes CBCT uniquely useful in the diagnosis of alveolar fractures. ${ }^{34-36}$

CBCT also eases the surgeon's decision making regarding whether a fracture exists or not. The diagnostic certainty is higher for the surgeon that uses CBCT imaging compared to conventional radiography. ${ }^{37}$ Contrary to this statement, Sirin et $\mathrm{al}^{38}$ found no statistically significant difference between CBCT and MSCT in artificially created condylar fractures of 63 sheep. However, the authors recommend the use of CBCT as a confirmatory imaging modality in maxillofacial trauma. Furthermore, 3D imaging captures skeletal and soft tissue details. Both can be displayed together to examine the relationship between a fracture and soft tissue, or they can be displayed individually to examine the details of either. A single CBCT following a traumatic event quickly captures a significant amount of patient information, which is useful for diagnosis.

\section{Bone graft analysis}

Volumetric analysis offers better prediction of defect morphology, like in the case of a cleft palate. Understanding the morphology of a traumatic defect is critical in developing the implant site before planned implant placement. Defect size and shape affect the factors that guide treatment-planning decisions. For example, defect size and shape form the basis for calculating how much graft material is needed, for predicting the likely stability of the postgraft arch, for estimating the quality of the bone graft over time and, in growing patients, for predicting how treatment will affect overall facial growth. ${ }^{39}$

\section{Temporomandibular joint assessment}

The diagnosis and treatment planning of TMJ disorders are often quite challenging. Although MRI remains the gold standard for imaging the intra-articular components of the TMJ, evaluation of its bony components is often left to conventional panoramic radiographs. ${ }^{40}$ Panoramic radiographs can provide a general impression of the joint in two dimensions, but they have low sensitivity in evaluating changes in the condyle, and they also have poor reliability and low accuracy in evaluating the temporal components of the joint. ${ }^{41}$ Current CBCT machines have been shown to provide a complete radiographic evaluation of the bony components of the TMJ. ${ }^{41}$ The resulting images are of high diagnostic quality.

A recent study suggests that CBCT should be considered as a complementary method of imaging when limitations in mandibular movement and function, stiffness of the jaw, and pain in the TMJ upon palpation are present, and when it is not possible to visualize the articular eminence upon panoramic radiography. ${ }^{42}$ Given the significantly reduced radiation dose and cost compared with conventional CT, CBCT may soon become the investigational tool of choice for evaluating bony changes of the TMJ. ${ }^{40}$

\section{Craniofacial surgery}

Cleft lip and palate pose unique challenges to dentists. ${ }^{43}$ Timely treatment of a cleft lip and palate is of paramount importance. Due to the young age of the patients and concerns surrounding radiation exposure, conventional CT is not always used. ${ }^{43}$ Panoramic and occlusal radiographs are used to evaluate the extent of cleft, but sometimes minor defects are concealed by conventional imaging. Other considerations include palatal 
expansion, as well as segmental alignment. CBCT allows for the better evaluation of dental age, arch segment positioning, and cleft size compared with traditional radiography. ${ }^{39}$ Albuquerque et $\mathrm{al}^{43}$ demonstrated that MSCT and CBCT are reliable techniques in the volumetric assessment of bone defects in the alveolar and palatal regions.

\section{Orthognathic surgery}

Lateral cephalography has been long considered the standard imaging modality when diagnosing skeletal and dental deformities. ${ }^{43}$ Superimposition of the right and left side, along with machine magnification, accurate surgical prediction, and treatment planning is difficult. With the advent of 3D imaging like CBCT, a 3D model can be virtually created and reliably adopted for orthodontic and orthognathic analysis, thereby accurately predicting the surgical protocol and the final prognosis. Complicated cases like hemifacial microsomia severe facial asymmetries that were previously considered to be difficult cases - are now planned and treated with geometric accuracy. ${ }^{39}$ Three-dimensional imaging of the hard and soft tissue makes all of the images available; the only question is how best to apply and manipulate that data for more accurate surgery and treatment planning. ${ }^{39}$ With the FaceScanner integrated in certain CBCT machines like GALILEOS (Sirona Dental GmbH, Bensheim, Germany), a virtual "mirror image" of the patient is plotted. The X-ray scan and 3D face scan are superimposed, fully automatically and accurately, thus proving to be great patient education tools, and they can also assist surgeons in treatment planning.
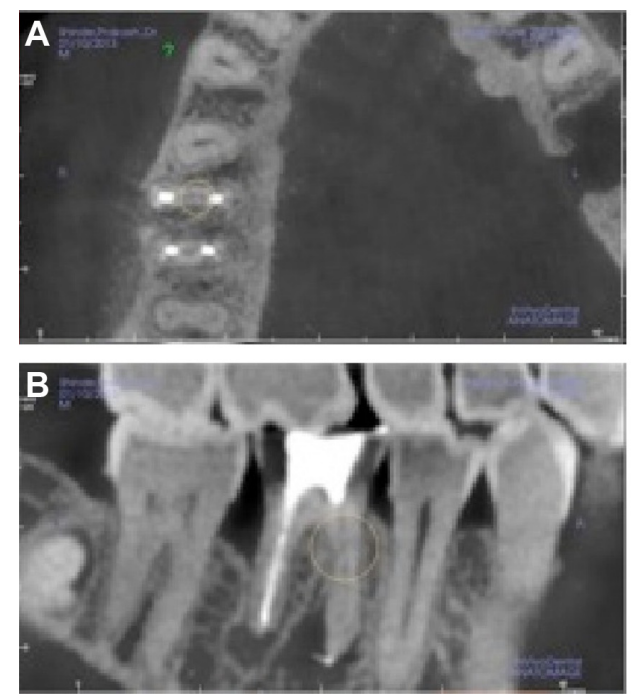

\section{Cone beam CT in endodontics}

Radiography is essential to the successful diagnosis of odontogenic and nonodontogenic pathoses, biomechanical instrumentation, final canal obturation, and in the assessment of healing. ${ }^{44}$ Imaging serves at all stages in endodontics. ${ }^{44}$ In endodontics, a machine with a limited FOV should suffice. In general, the smaller the scan volume, the higher the spatial resolution of the image. Given that the earliest sign of periapical pathology is discontinuity in the lamina dura and widening of the periodontal ligament space, it is desirable that the optimal resolution of any CBCT imaging system that is used in endodontics not exceed $200 \mu \mathrm{m}$ - the average width of the periodontal ligament space. It has been reported that when comparing intraoral radiography, panoramic radiography, computerized radiography, and digital volume tomography with histologic specimens, CBCT has been shown to display the periodontal ligament space more accurately. ${ }^{45}$ The 3D Accuitomo (J Morita USA, Inc.) - the first of the small FOV systems - provided a resolution of $0.125 \mathrm{~mm} .{ }^{44}$

\section{Assessment of root canal morphology}

The success of endodontic treatment depends on the identification of all root canals so that they can be accessed, cleaned, shaped, and obturated. ${ }^{46}$ The prevalence of a second mesiobuccal canal (MB2) in the maxillary first molars has been reported to vary from $69 \%-93 \%$, depending on the study method employed (Figure 6). This variability occurs in the buccolingual plane, where the superimposition of anatomic structures impedes the detection of small structural
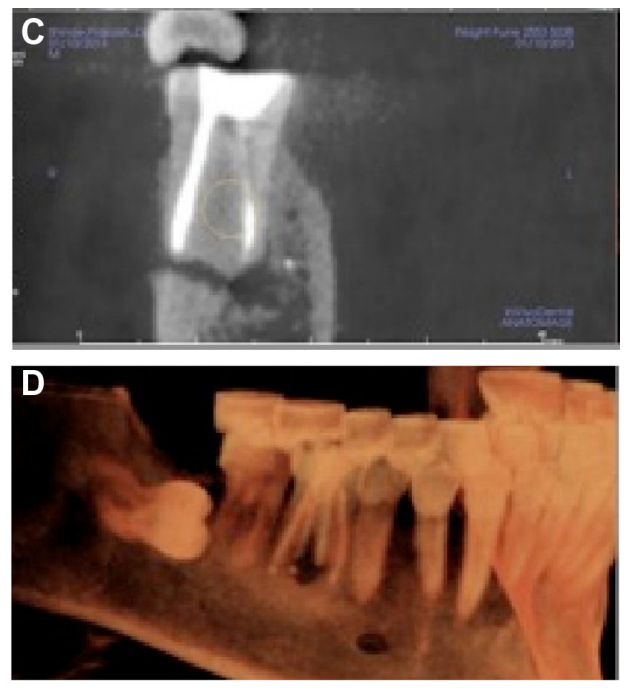

Figure 6 CBCT image showing the missed canal in the mandibular molar.

Notes: Images courtesy of Dr Niranjan Vatkar, endodontist, Pune, India. (A) Missed canal seen on axial view. (B) Sagittal view showing large radiolucent lesion with mandibular first molar. (C) Cross sectional view showing missed canal. (D) 3D reconstruction showing osteolytic lesion with mandibular first molar. Abbreviation: $\mathrm{CBCT}$, cone-beam computed tomography. 
density changes ${ }^{47,48}$ Conventional radiographic techniques, at best, can only detect up to $55 \%$ of these configurations. ${ }^{49}$

Ramamurthy et $\mathrm{al}^{49}$ and Matherne et $\mathrm{al}{ }^{50}$ have described the limitations of 2D imaging in the detection of the MB2 canal. A study conducted by Neelakantan et $\mathrm{al}^{51}$ in an Indian population revealed that the number of MB2 canals was more apparent in the maxillary first molar, as compared to the second molar. Also, type 4 canal anatomy was more prevalent when compared to the Mongoloid population. ${ }^{51}$

Baratto Filho et $a^{52}$ investigated the internal morphology of extracted maxillary first molars by comparing their detection rates, as obtained using an operating microscope and $\mathrm{CBCT}$ to ex vivo sections. The authors reported an ex vivo prevalence of a fourth canal in $67.14 \%$ of teeth and additional root canals in $92.85 \%$ of mesiobuccal roots. Clinical assessment provided slightly lower overall (53.26\%), but higher (95.63\%), MB2 detection rates, whereas CBCT results showed the lowest overall $(37.05 \%)$ detection rate. The authors further indicated that CBCT provided a good method for the initial evaluation of maxillary first molar internal morphology, but that the use of operating microscopes was optimal. CBCT imaging has also been reported to characterize the high prevalence of the distolingual canal in Taiwanese individuals, it highlights anomalies in the root canal system of mandibular premolars, and it assists in the determination of root curvature. ${ }^{53,54}$ Some authors also wish to report on the variations in mandibular incisor anatomy, as detected in an Indian population by CBCT. ${ }^{55}$

With the advent of newer software provided by CBCT companies like ORTHOPHOS XG3D/GALILEOS (Sirona Dental $\mathrm{GmbH}$ ), working length determination of the root canal can be performed. However, its clinical success and accuracy in clinical setup needs to be evaluated.

\section{Dental periapical pathoses}

The most common pathologic conditions that involve teeth are inflammatory lesions of the pulp and periapical areas. ${ }^{4}$ $\mathrm{CBCT}$ technology now provides the clinician with the ability to observe an area in three different planes, and thus he or she can acquire 3D information. Lesions confined to cancellous bone with little or no cortical plate erosion can be difficult to diagnose with intraoral film. ${ }^{4}$ Lofthag-Hansen et al ${ }^{56,57}$ compared the accuracy of limited FOV CBCT to an intraoral radiographic paralleling technique. The authors reported that CBCT provides greater diagnostic accuracy (61\%) compared with digital (39\%) and conventional (44\%) radiographs. They also indicated that while detection rates for CBCT were higher, they did not advocate the replacement of intraoral radiography for detecting periapical lesions in routine clinical practice due to financial and dose considerations.

$\mathrm{CBCT}$, when compared with periapical and panoramic radiography, detected apical periodontitis at a higher rate. ${ }^{58}$ Estrela et a $1^{58}$ proposed a periapical index based on CBCT for the identification of apical periodontitis (AP). The CBCT periapical index is a six-point (0-5) scoring system calculated from determining the largest lesional measurement in either the buccopalatal, mesiodistal, or diagonal dimension, and it also takes into account expansion and destruction of cortical bone. The index is outlined in Table 3 .

Using this periapical index, Low et $\mathrm{al}^{59}$ concluded that CBCT performed better in the detection of periapical lesions compared with conventional imaging. CBCT technology and the assignment of gray values might aid in the diagnosis of cysts versus granulomas. ${ }^{44}$ The generally higher detection rates afforded by CBCT are similar to those reported for conventional $\mathrm{CT} .{ }^{44}$ This may be of clinical importance in patients who present with pain or who have poorly localized symptoms associated with an untreated or previously roottreated tooth with no evidence of a pathology, as identified by conventional imaging. ${ }^{44}$

\section{Root fractures}

The usefulness and importance of CBCT in the diagnosis and management of specific aspects of dentoalveolar trauma, especially root fractures, luxation, displacement, and alveolar fracture, has been studied extensively. ${ }^{60,61}$

The superiority of CBCT in the detection of vertical and horizontal root fractures has been described in the literature. ${ }^{62,63}$ Elimination of superimposition of anatomic structures allows the clinician to analyze the fracture clearly. Authors recommend the use of limited CBCT for the detection of horizontal root fractures when compared with conventional imaging (Figure 7).

Table 3 CBCT periapical index

\begin{tabular}{ll}
\hline Score & $\begin{array}{l}\text { Quantitative bone alterations in mineral } \\
\text { structures }\end{array}$ \\
\hline 0 & Intact periapical bone structures \\
$\mathrm{I}$ & Diameter of periapical radiolucency $>0.5-1 \mathrm{~mm}$ \\
2 & Diameter of periapical radiolucency $>1-2 \mathrm{~mm}$ \\
3 & Diameter of periapical radiolucency $>2-4 \mathrm{~mm}$ \\
4 & Diameter of periapical radiolucency $>4-8 \mathrm{~mm}$ \\
5 & Diameter of periapical radiolucency $>8 \mathrm{~mm}$ \\
$+\mathrm{E}$ & Expansion of periapical cortical bone \\
$+\mathrm{D}$ & Destruction of periapical cortical bone \\
\hline
\end{tabular}

Abbreviation: $\mathrm{CBCT}$, cone-beam computed tomography. 


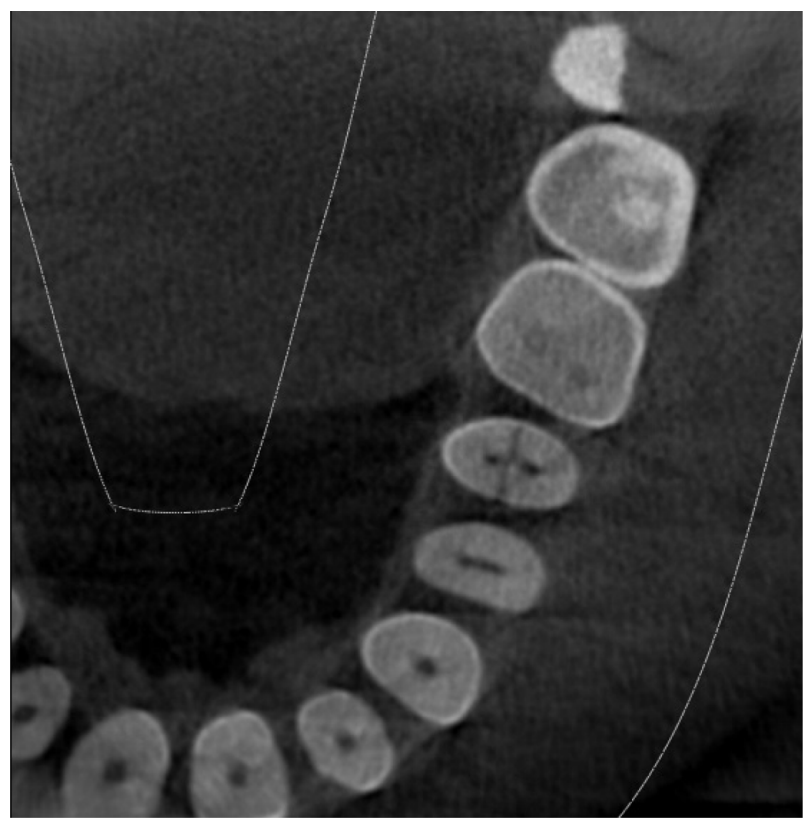

Figure 7 Axial view of $C B C T$ showing the fracture line on the upper-right second premolar.

Abbreviation: $\mathrm{CBCT}$, cone-beam computed tomography.

\section{Root resorption}

Root resorption is the loss of dental hard tissues as a result of clastic activities. It might occur as a physiologic or pathologic phenomenon. ${ }^{64}$ Root resorption might be broadly classified into external or internal resorption by the location of the resorption in relation to the root surface. The accuracy of CBCT in the detection of surface defects, while higher than conventional imaging modalities, is not perfect, and appears to increase with increasing voxel resolution of the volumetric dataset (greater resolution is achieved with increased voxel size). ${ }^{44} \mathrm{CBCT}$ has also been shown to have particular applications in the assessment of the postorthodontic apical root resorption and, in particular, of the roots of lateral maxillary incisors impacted by maxillary canines. ${ }^{44}$

$\mathrm{CBCT}$ has been used successfully to confirm the presence of internal root resorption and it can differentiate this type of resorption from external root resorption. ${ }^{65}$ Conventional radiography is often unable to identify the true extent, location, or the portal of entry of a resorptive lesion. ${ }^{44} \mathrm{CBCT}$ has been shown to help determine treatment complexity, as well as aid the clinician in offering an accurate prognosis on the basis of the extent of the resorptive lesion. ${ }^{44} \mathrm{As}$ a result, both treatment and treatment outcomes are likely to become more predictable. ${ }^{44}$

\section{Postoperative assessment}

Monitoring the healing of apical lesions is an important aspect of postoperative assessment in endodontics. Similarly, the adequacy of root canal obturation is an important determinant of endodontic success; it might be considered that CBCT is used in the initial and subsequent monitoring of the integrity of root canal fillings. Soğur et $\mathrm{al}^{66}$ reported that the images acquired from phosphor plates and conventional films were better when compared to CBCT images, as the presence of streaking artifacts from the gutta percha and the sealer compromise the quality of those images with regards to root filling evaluations. The utility of $\mathrm{CBCT}$ in determining the precise nature of a perforation and the role of this on subsequent treatment has been illustrated by Young. ${ }^{67}$

Preoperative assessment of the periapical surgical site is of utmost importance to avoid postoperative complications. Proximity to the mandibular canal, mental foramen, and maxillary sinus during periapical surgery can be assessed accurately on CBCT images. Jaju ${ }^{44}$ first described the value of $\mathrm{CBCT}$ in the planning of endodontic surgery. The importance of CBCT for apical surgery of the teeth adjacent to the maxillary sinus has subsequently been illustrated by Jaju, ${ }^{44}$ who presented a case report localizing the presence of a periradicular lesion to a specific root.

\section{Recommendation of the $A A E$ and AAOMR}

The following are recommendations from the American Association of Endodontists (AAE) and AAOMR: ${ }^{68}$

- Identification of potential accessory canals in teeth with suspected complex morphology based on conventional imaging.

- Identification of root canal system anomalies and determination of root curvature.

- Diagnosis of dental periapical pathosis in patients who present with contradictory or nonspecific clinical signs and symptoms, who have poorly localized symptoms associated with an untreated or previously endodontically treated tooth with no evidence of pathosis, as identified by conventional imaging, and in cases where anatomic superimposition of roots or areas of the maxillofacial skeleton is required to perform task-specific procedures.

- Diagnosis of nonendodontic origin pathosis in order to determine the extent of the lesion and its effect on surrounding structures.

- Intra- or postoperative assessment of endodontic treatment complications, such as overextended root canal obturation material, separated endodontic instruments, calcified canal identification, and localization of perforations. 
- Diagnosis and management of dentoalveolar trauma, especially root fractures, luxation and/or displacement of teeth, and alveolar fractures.

- Localization and differentiation of external and internal root resorption, or invasive cervical resorption from other conditions, and the determination of appropriate treatment and prognosis.

- Presurgical case planning to determine the exact location of the root apex/apices and to evaluate the proximity of adjacent anatomical structures.

- Dental implant case planning when cross-sectional imaging is deemed essential, as based on the clinical evaluation of the edentulous ridge.

\section{Applications in orthodontics}

The introduction of new software in orthodontic assessment, such as Dolphin (Dolphin Imaging and Management Solutions, Chatsworth, CA, USA) and Invivo Dental (Anatomage, San Jose, CA, USA), has allowed dentists to use CBCT images for cephalometric analysis, making it the tool of choice for assessing facial growth, age, airway function, and disturbances in tooth eruption. ${ }^{69}$ Katkar et al, ${ }^{70}$ in their study, confirmed that $\mathrm{CBCT}$ was reliable in demonstrating cephalometric landmarks accurately.

Moreira et $\mathrm{al}^{71}$ verified the accuracy of linear measurements from CBCT cephalograms and compared them to traditional cephalograms. CBCT proved to be more accurate than lateral cephalogram when compared to skull measurement. ${ }^{71}$

CBCT is a reliable tool for assessing the proximity of impacted teeth to vital structures that could interfere with orthodontic movement. ${ }^{72}$ When mini-implants are required as temporary anchors, CBCT offers visual guides for safe insertion, thus avoiding accidental and irreparable damage to the existing roots. ${ }^{73}$ Assessing bone density before, during, and after treatment can show whether it is decreasing or remaining the same. ${ }^{73} \mathrm{CBCT}$ images are self-corrected for magnification, producing orthogonal images with a practical 1:1 measuring ratio; as a result, CBCT is considered a more accurate option than panoramic and traditional $2 \mathrm{D}$ images. $^{73}$

\section{CBCT in periodontics}

According to Vandenberghe et al, ${ }^{74}$ intraoral radiography is the most common imaging modality used for diagnosing bone morphology, such as periodontal bone defects. However, the limitations of 2D radiography could underestimate the amount of bone loss or available bone due to projection errors. ${ }^{74}$ These findings confirm the observation by Alamri et al, ${ }^{73}$ that $2 \mathrm{D}$ radiographs are inadequate for detecting changes at the bone level or for determining the architecture of osseous defects. CBCT provides accurate measurements of intrabony defects and allows clinicians to assess dehiscence, fenestration defects, and periodontal cysts. ${ }^{73} \mathrm{CBCT}$ has been used to obtain detailed morphologic descriptions of bone that are as accurate as those obtained via direct measurement with a periodontal probe. ${ }^{73} \mathrm{CBCT}$ can also be used to assess furcation involvement of periodontal defects and allow clinicians to evaluate the postsurgical results of regenerative periodontal therapy. ${ }^{73}$

Moreira et $\mathrm{al}^{71}$ investigated the accuracy of CBCT in linear measurements of bone defects and concluded that CBCT can be an accurate diagnostic tool for the evaluation of small osseous defects. The authors are of the view that more scientific literature is required to conclusively prove that $\mathrm{CBCT}$ is a more superior imaging technology that can be utilized in periodontal applications.

\section{CBCT in operative dentistry}

Higher radiation dose and lower resolution of CBCT compared with intraoral radiography hampers its role in the detection of occlusal caries. ${ }^{3}$

\section{Applications in forensic dentistry}

Age estimation is an important aspect of forensic dentistry. The pulpo-dentinal complex (dentin, cementum, and the dental pulp) shows physiologic and pathological changes with advancing age. ${ }^{72}$ Typically, extraction and sectioning are required to quantify these morphological changes, which is not always a viable option. ${ }^{75} \mathrm{CBCT}$, however, provides a noninvasive alternative. ${ }^{75}$

The visualization of cervical vertebral morphology holds potential in skeletal age assessment. Shi et al, ${ }^{76}$ in their study, concluded that segmentation of individual vertebrae was possible using CBCT volumetric datasets. This provides a 3D approach to the biologic aging of orthodontic patients by using images of the cervical spine. It also holds potential in studying disease processes such as spinal fractures consequent to osteoporosis. ${ }^{76}$

\section{CBCT in obstructive sleep apnea (OSA)}

OSA is a common respiratory sleep disorder characterized by snoring and episodes of breathing cessation or the absence of respiratory airflow (10 seconds) during sleep, 
despite respiratory effort. ${ }^{77}$ Any technology that would enhance clinicians' ability to visualize where in the airway obstruction occurs would help identify those subsets of patients who may or may not benefit from a choice of treatment modalities. CBCT, with its 3D presentation of the airway and the airway's surrounding structures, offers this increased visualization of both untreated obstruction tendencies and potentially of changes in the airway by treatment modality. Ogawa et $\mathrm{al}^{78}$ demonstrated the utility of the diagnosis of anatomy with the 3D airway imaging with CBCT (CBCT allows to visualize the anatomy of airspace in three dimension and helps in the diagnosis of any anatomic variation or diseases). They noted the ability to describe significant group differences in total airway volume and the anteroposterior dimension of the oropharyngeal airway between OSA and sex-matched controls. ${ }^{78}$ Farman et $\mathrm{al}^{79}$ examined the possibilities of using different software packages to analyze changes in the upper airway with and without placement of a mandibular advancement device. Excellent segmentation was achieved, and it was possible to make airway minimum cross-sectional area and volumetric assessment.

\section{CBCT in ear imaging (ENT)}

Improvement in CBCT technology has revolutionized not only dentomaxillofacial imaging, but it has also improved imaging in the field of ENT.

\section{Sinuses and nasal fossae}

Higher resolution images and operator-friendly CBCT software with multiplanar reformation (MPR) visualization of each examination make them particularly practical in understanding sinonasal anatomy. ${ }^{80}$

\section{Inflammatory pathology}

CBCT shows excellent air-mucosa-bone contrast, allowing for the very interesting study of air cavity anatomy and ventilation. ${ }^{81}$ Effusion, mucosal thickening, and ostial obstruction are perfectly visible, with precision equal to or greater than that of $\mathrm{CT}^{81}$ Any inflammatory or infectious sinus pathology is accessible to CBCT examination, with complete topographic exploration. ${ }^{81}$ However, as with $\mathrm{CT}$ without contrast injection, it is not possible to distinguish between simple mucosal thickening, mucosal cysts, polyps, and retention cysts (Figure 8).

\section{Fungal sinusitis}

With the introduction of metal artifact reduction software and good spatial resolution enable the detection of fine

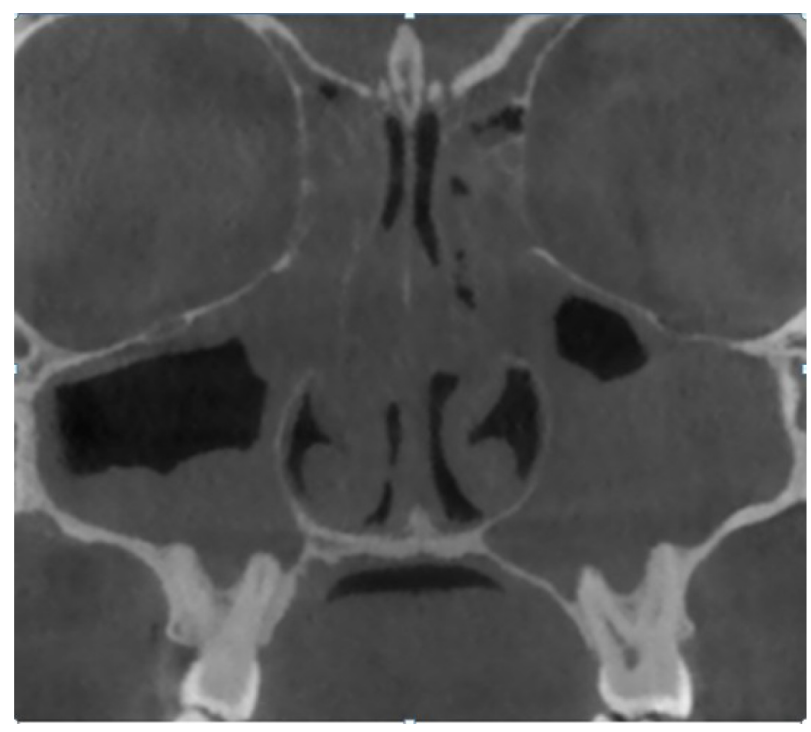

Figure $8 \mathrm{CBCT}$ coronal image showing pansinusitis.

Note: Image courtesy of Dr Shikha Rathi Diplomat (AAOMR, USA).

Abbreviations: $\mathrm{CBCT}$, cone-beam computed tomography; AAOMR, American Academy of Oral and Maxillofacial Radiology.

calcifications associated with Aspergillus grafts around intrasinus metallic foreign bodies, usually of dental origin. ${ }^{81}$

\section{Bone remodeling and mucosal calcification}

The study of fine bone remodeling requires good spatial resolution. This is the case for the assessment of bone extension of infectious processes of dental or sinus origin, fine perforation, intraosseous fistular trajectories, and thinning or blurring of walls. ${ }^{81}$ Mucosal calcification along the wall by the osseous metaplasia of Schneider's membrane during subacute or chronic inflammatory processes can also be detected. ${ }^{81}$

\section{Postoperative assessment}

$\mathrm{CBCT}$, with its low radiation intensity, is well adapted for postoperative follow-up. It is, of course, restricted to benign sinus lesion surgeries, with CT and MRI still used for the postoperative follow-up of malignancies. ${ }^{81}$

\section{Tumoral pathology}

If a tumor invading the soft tissue is discovered, CT and/or $\mathrm{MRI}$ are mandatory. CBCT without contrast enables excellent topographic study of bone extension, any intratumoral calcification, or of the perilesional thin osseous wall. ${ }^{81}$

\section{Temporal bone/cranial base aspect on cone-beam image}

A lower signal-to-noise ratio gives a slightly different aspect than on reference (CT) imaging. ${ }^{81}$ The esthetic and diagnostic 
qualities of an image, however, are not the same thing. CBCT gives access to plentiful and sufficient diagnostic information if the indications for $\mathrm{CBCT}$ are correct. It should always be borne in mind that minimal radiation is an important factor in indications for imaging assessment by $\mathrm{X}$-ray, and that radiation-free or radiation-light techniques of equal diagnostic quality should always be preferred. ${ }^{82}$

\section{Conclusion}

While clinical applications of CBCT have expanded, current $\mathrm{CBCT}$ technology has limitations related to the projection geometry, detector sensitivity, and contrast resolution that produce images that lack the clarity and usefulness of conventional CT images. The clarity of CBCT images is affected by artifacts, noise, and poor soft tissue contrast. With software improvements, these limitations would be gradually overcome in the future. It is also necessary to respect the "as low as reasonably achievable" radiation dose concept. However, this should not deter dental surgeons from utilizing CBCT for providing necessary information. Some authors are of the opinion that the judicious use of CBCT technology can outweigh inherent risks over its extraordinary benefits. Proper training and education in CBCT for oral maxillofacial radiologists and dentists is required to ensure astute use of CBCT technology.

\section{Acknowledgments}

The authors wish to thank Dr Niranjan Vatkar, Dr Shikha Rathi, and JSD Technodent, Bangalore, India for providing CBCT images.

\section{Disclosure}

The authors report no conflicts of interest in this work.

\section{References}

1. Tyndall DA, Rathore S. Cone-beam CT diagnostic applications: caries, periodontal bone assessment, and endodontic applications. Dent Clin North Am. 2008;52(4):825-841, vii.

2. Zoller JE, Neugebauer J. Cone-Beam Volumetric Imaging in Dental, Oral and Maxillofacial Medicine: Fundamentals, Diagnostics and Treatment Planning. Chicago, IL: Quintessence Publishing; 2008.

3. Tetradis S, Anstey P, Graff-Radford S. Cone beam computed tomography in the diagnosis of dental disease. $J$ Calif Dent Assoc. 2010;38(1):27-32.

4. Tyndall DA, Price JB, Tetradis S, Ganz SD, Hildebolt C, Scarfe WC; American Academy of Oral and Maxillofacial Radiology. Position statement of the American Academy of Oral and Maxillofacial Radiology on selection criteria for the use of radiology in dental implantology with emphasis on cone beam computed tomography. Oral Surg Oral Med Oral Pathol Oral Radiol. 2012;113(6):817-826.

5. Macleod I, Heath N. Cone-beam computed tomography (CBCT) in dental practice. Dent Update. 2008;35(9):590-592, 594.

6. Howerton WB, Mora MA. Advancements in digital imaging: what is new and on the horizon? J Am Dent Assoc. 2008;139 Suppl:20S-24S.
7. Dreiseidler T, Mischkowski RA, Neugebauer J, Ritter L, Zöller JE. Comparison of cone-beam imaging with orthopantomography and computerized tomography for assessment in presurgical implant dentistry. Int J Oral Maxillofac Implants. 2009;24(2):216-225.

8. Tischler M. In-office cone beam computerized tomography: technology review and clinical examples. Dent Today. 2008;27(6):102, 104, 106.

9. Loubele M, Van Assche N, Carpentier K, et al. Comparative localized linear accuracy of small-field cone-beam CT and multislice CT for alveolar bone measurements. Oral Surg Oral Med Oral Pathol Oral Radiol Endod. 2008;105(4):512-518.

10. Jaju PP, Jaju SP, Suvarna PV, Dedhia P, editors. Dental CT: Third Eye in Dental Implants. New Delhi, India: Jaypee Brothers Medical Publishers Ltd; 2013.

11. Lindh C, Obrant K, Petersson A. Maxillary bone mineral density and its relationship to the bone mineral density of the lumbar spine and hip. Oral Surg Oral Med Oral Pathol Oral Radiol Endod. 2004;98(1):102-109.

12. Drage NA, Palmer RM, Blake G, Wilson R, Crane F, Fogelman I. A comparison of bone mineral density in the spine, hip and jaws of edentulous subjects. Clin Oral Implants Res. 2007;18(4):496-500.

13. Lekholm U, Zarb GA. Patient selection and preparation. In: Brånemark PI, Zarb GA, Albrektsson T, editors. Tissue-Integrated Prostheses: Osseointegration in Clinical Dentistry. Chicago, IL: Quintessence Publishing; 1985:199-209.

14. Molteni R. Prospects and challenges of rendering tissue density in Hounsfield units for cone beam computed tomography. Oral Surg Oral Med Oral Pathol Oral Radiol. 2013;116(1):105-119.

15. Orentlicher G, Abboud M. Guided surgery for implant therapy. Dent Clin North Am. 2011;55(4):715-744.

16. Chau AC, Fung K. Comparison of radiation dose for implant imaging using conventional spiral tomography, computed tomography, and cone-beam computed tomography. Oral Surg Oral Med Oral Pathol Oral Radiol Endod. 2009;107(4):559-565.

17. Miracle AC, Mukherji SK. Conebeam CT of the head and neck, part 2: clinical applications. AJNR Am J Neuroradiol. 2009;30(7): $1285-1292$.

18. Adibi S, Zhang W, Servos T, O'Neill P. Cone beam computed tomography for general dentists. Open Access Scientific Reports. 2012;1:519.

19. Suomalainen A, Ventä I, Mattila M, Turtola L, Vehmas T, Peltola JS. Reliability of CBCT and other radiographic methods in preoperative evaluation of lower third molars. Oral Surg Oral Med Oral Pathol Oral Radiol Endod. 2010;109(2):276-284.

20. Ghaeminia H, Meijer GJ, Soehardi A, Borstlap WA, Mulder J, Bergé SJ. Position of the impacted third molar in relation to the mandibular canal. Diagnostic accuracy of cone beam computed tomography compared with panoramic radiography. Int J Oral Maxillofac Surg. 2009;38(9):964-971.

21. Kamrun N, Tetsumura A, Nomura Y, et al. Visualization of the superior and inferior borders of the mandibular canal: a comparative study using digital panoramic radiographs and cross-sectional computed tomography images. Oral Surg Oral Med Oral Pathol Oral Radiol. 2013;115(4):550-557.

22. Tantanapornkul W, Okouchi K, Fujiwara Y, et al. A comparative study of cone-beam computed tomography and conventional panoramic radiography in assessing the topographic relationship between the mandibular canal and impacted third molars. Oral Surg Oral Med Oral Pathol Oral Radiol Endod. 2007;103(2):253-259.

23. Leifert S, Jonas IE. Dental anomalies as a microsymptom of palatal canine displacement. J Orofac Orthop. 2003;64(2):108-120.

24. Liu DG, Zhang WL, Zhang ZY, Wu YT, Ma XC. Localization of impacted maxillary canines and observation of adjacent incisor resorption with cone-beam computed tomography. Oral Surg Oral Med Oral Pathol Oral Radiol Endod. 2008;105(1):91-98.

25. Stewart JA, Heo G, Glover KE, Williamson PC, Lam EW, Major PW. Factors that relate to treatment duration for patients with palatally impacted maxillary canines. Am J Orthod Dentofacial Orthop. 2001;119(3):216-225. 
26. Fournier A, Turcotte JY, Bernard C. Orthodontic considerations in the treatment of maxillary impacted canines. Am J Orthod. 1982;81(3): 236-239.

27. Ericson S, Kurol J. Radiographic assessment of maxillary canine eruption in children with clinical signs of eruption disturbance. Eur $J$ Orthod. 1986;8(3):133-140.

28. Walker L, Enciso R, Mah J. Three-dimensional localization of maxillary canines with cone-beam computed tomography. Am J Orthod Dentofacial Orthop. 2005;128(4):418-423.

29. Alqerban A, Hedesiu M, Baciut M, et al; SedentexCT Consortium. Pre-surgical treatment planning of maxillary canine impactions using panoramic vs cone beam CT imaging. Dentomaxillofac Radiol. 2013;42(9):20130157.

30. Guttenberg SA. Oral and maxillofacial pathology in three dimensions. Dent Clin North Am. 2008;52(4):843-873, viii.

31. Marques YM, Botelho TD, Xavier FC, Rangel AL, Rege IC, Mantesso A. Importance of cone beam computed tomography for diagnosis of calcifying cystic odontogenic tumour associated to odontoma. Report of a case. Med Oral Patol Oral Cir Bucal. 2010;15(3): e490-e493.

32. Hendrikx AW, Maal T, Dieleman F, Van Cann EM, Merkx MA. Cone-beam $\mathrm{CT}$ in the assessment of mandibular invasion by oral squamous cell carcinoma: results of the preliminary study. Int J Oral Maxillofac Surg. 2010;39(5):436-439.

33. Dreiseidler T, Alarabi N, Ritter L, et al. A comparison of multislice computerized tomography, cone-beam computerized tomography, and single photon emission computerized tomography for the assessment of bone invasion by oral malignancies. Oral Surg Oral Med Oral Pathol Oral Radiol Endod. 2011;112(3):367-374.

34. Palomo L, Palomo JM. Cone beam CT for diagnosis and treatment planning in trauma cases. Dent Clin North Am. 2009;53(4): 717-727, vi.

35. Heiland M, Schulze D, Rother U, Schmelzle R. Postoperative imaging of zygomaticomaxillary complex fractures using digital volume tomography. J Oral Maxillofac Surg. 2004;62(11): 1387-1391.

36. Mischkowski RA, Zinser MJ, Ritter L, Neugebauer J, Keeve E, Zöller JE. Intraoperative navigation in the maxillofacial area based on 3D imaging obtained by a cone-beam device. Int J Oral Maxillofac Surg. 2007;36(8):687-694.

37. Kaeppler G, Cornelius CP, Ehrenfeld M, Mast G. Diagnostic efficacy of cone-beam computed tomography for mandibular fractures. Oral Surg Oral Med Oral Pathol Oral Radiol. 2013;116(1):98-104.

38. Sirin Y, Guven K, Horasan S, Sencan S. Diagnostic accuracy of cone beam computed tomography and conventional multislice spiral tomography in sheep mandibular condyle fractures. Dentomaxillofac Radiol. 2010;39(6):336-342.

39. Quereshy FA, Savell TA, Palomo JM. Applications of cone beam computed tomography in the practice of oral and maxillofacial surgery. J Oral Maxillofac Surg. 2008;66(4):791-796.

40. Tsiklakis K, Syriopoulos K, Stamatakis HC. Radiographic examination of the temporomandibular joint using cone beam computed tomography. Dentomaxillofac Radiol. 2004;33(3):196-201.

41. Dahlström L, Lindvall AM. Assessment of temporomandibular joint disease by panoramic radiography: reliability and validity in relation to tomography. Dentomaxillofac Radiol. 1996;25(4):197-201.

42. de Boer EW, Dijkstra PU, Stegenga B, de Bont LG, Spijkervet FK. Value of cone-beam computed tomography in the process of diagnosis and management of disorders of the temporomandibular joint. Br J Oral Maxillofac Surg. 2014;52(3):241-246.

43. Albuquerque MA, Gaia BF, Cavalcanti MG. Comparison between multislice and cone-beam computerized tomography in the volumetric assessment of cleft palate. Oral Surg Oral Med Oral Pathol Oral Radiol Endod. 2011;112(2):249-257.

44. Jaju SP. Cone beam CT in endodontics: a paradigm shift in clinical practice. Smile Dental Journal. 2013;8(2):22-28.
45. Jervøe-Storm PM, Hagner M, Neugebauer J, et al. Comparison of cone-beam computerized tomography and intraoral radiographs for determination of the periodontal ligament in a variable phantom. Oral Surg Oral Med Oral Pathol Oral Radiol Endod. 2010;109(2): e95-e101.

46. Vertucci FJ. Root canal anatomy of the human permanent teeth. Oral Surg Oral Med Oral Pathol. 1984;58(5):589-599.

47. Pineda F. Roentgenographic investigation of the mesiobuccal root of the maxillary first molar. Oral Surg Oral Med Oral Pathol. 1973;36(2):253-260

48. Nance R, Tyndall D, Levin LG, Trope M. Identification of root canals in molars by tuned-aperture computed tomography. Int Endod J. 2000;33(4):392-396.

49. Ramamurthy R, Scheetz JP, Clark SJ, Farman AG. Effects of imaging system and exposure on accurate detection of the second mesio-buccal canal in maxillary molar teeth. Oral Surg Oral Med Oral Pathol Oral Radiol Endod. 2006;102(6):796-802.

50. Matherne RP, Angelopoulos C, Kulild JC, Tira D. Use of cone-beam computed tomography to identify root canal systems in vitro. J Endod. 2008;34(1):87-89.

51. Neelakantan P, Subbarao C, Ahuja R, Subbarao CV, Gutmann JL. Cone-beam computed tomography study of root and canal morphology of maxillary first and second molars in an Indian population. $J$ Endod. 2010;36(10):1622-1627.

52. Baratto Filho F, Zaitter S, Haragushiku GA, de Campos EA, Abuabara A, Correr GM. Analysis of the internal anatomy of maxillary first molars by using different methods. J Endod. 2009;35(3):337-342.

53. Tu MG, Huang HL, Hsue SS, et al. Detection of permanent threerooted mandibular first molars by cone-beam computed tomography imaging in Taiwanese individuals. J Endod. 2009;35(4): 503-507

54. Cleghorn BM, Christie WH, Dong CC. Anomalous mandibular premolars: a mandibular first premolar with three roots and a mandibular second premolar with a C-shaped canal system. Int Endod J. 2008;41(11):1005-1014.

55. Jaju SP, Jaju PP, Garcha V. Root canal assessment of mandibular incisors in an Indian population using cone beam CT. Endod Prac. 2013;7(2):105-111.

56. Estrela C, Bueno MR, Sousa-Neto MD, Pécora JD. Method for determination of root curvature radius using cone-beam computed tomography images. Braz Dent J. 2008;19(2):114-118.

57. Lofthag-Hansen S, Huumonen S, Gröndahl K, Gröndahl HG. Limited cone-beam CT and intraoral radiography for the diagnosis of periapical pathology. Oral Surg Oral Med Oral Pathol Oral Radiol Endod. 2007;103(1):114-119.

58. Estrela C, Bueno MR, Azevedo BC, Azevedo JR, Pécora JD. A new periapical index based on cone beam computed tomography. J Endod. 2008;34(11):1325-1331.

59. Low KM, Dula K, Bürgin W, von Arx T. Comparison of periapical radiography and limited cone-beam tomography in posterior maxillary teeth referred for apical surgery. J Endod. 2008;34(5):557-562.

60. Cohenca N, Simon JH, Roges R, Morag Y, Malfaz JM. Clinical indications for digital imaging in dento-alveolar trauma. Part 1: traumatic injuries. Dent Traumatol. 2007;23(2):95-104.

61. Ilgüy D, Ilgüy M, Fisekcioglu E, Bayirli G. Detection of jaw and root fractures using cone beam computed tomography: a case report. Dentomaxillofac Radiol. 2009;38(3):169-173.

62. Hassan B, Metska ME, Ozok AR, van der Stelt P, Wesselink PR. Detection of vertical root fractures in endodontically treated teeth by a cone beam computed tomography scan. J Endod. 2009;35(5): 719-722.

63. Kamburoğlu K, Ilker Cebeci AR, Gröndahl HG. Effectiveness of limited cone-beam computed tomography in the detection of horizontal root fracture. Dent Traumatol. 2009;25(3):256-261.

64. Patel S, Pitt Ford TR. Is the resorption external or internal? Dent Update. 2007;34:218-229. 
65. Cohenca N, Simon JH, Mathur A, Malfaz JM. Clinical indications for digital imaging in dento-alveolar trauma. Part 2: root resorption. Dent Traumatol. 2007;23(2):105-113.

66. Soğur E, Baksi BG, Gröndahl HG. Imaging of root canal fillings: a comparison of subjective image quality between limited cone-beam CT, storage phosphor and film radiography. Int Endod J. 2007;40(3): 179-185.

67. Young GR. Contemporary management of lateral root perforation diagnosed with the aid of dental computed tomography. Aust Endod J. 2007;33(3):112-118.

68. Joint Position Statement of the American Association of Endodontists and the American Academy of Oral and Maxillofacial Radiology. Use of Cone-Beam Computed Tomography in Endodontics. 2010. Available from: http://c.ymcdn.com/sites/www.aaomr.org/resource/resmgr/Docs/ AAOMR-AAE_postition_paper_CB.pdf.

69. Bjerklin K, Ericson S. How a computerized tomography examination changed the treatment plans of 80 children with retained and ectopically positioned maxillary canines. Angle Orthod. 2006;76:43-51.

70. Katkar RA, Kummet C, Dawson D, et al. Comparison of observer reliability of three-dimensional cephalometric landmark identification on subject images from Galileos and i-CAT cone beam CT. Dentomaxillofac Radiol. 2013;42(9):20130059.

71. Moreira CR, Sales MA, Lopes PM, Cavalcanti MG. Assessment of linear and angular measurements on three-dimensional cone-beam computed tomographic images. Oral Surg Oral Med Oral Pathol Oral Radiol Endod. 2009;108(3):430-436.

72. Erickson M, Caruso JM, Leggitt L. Newtom QR-DVT 9000 imaging used to confirm a clinical diagnosis of iatrogenic mandibular nerve paresthesia. J Calif Dent Assoc. 2003;31(11):843-845.

73. Alamri HM, Sadrameli M, Alshalhoob MA, Sadrameli M, Alshehri MA Applications of CBCT in dental practice: a review of the literature. Gen Dent. 2012;60(5):390-400; quiz 401.
74. Vandenberghe B, Jacobs R, Yang J. Diagnostic validity (or acuity) of 2D CCD versus 3D CBCT-images for assessing periodontal breakdown. Oral Surg Oral Med Oral Pathol Oral Radiol Endod. 2007;104(3): 395-401.

75. Yang F, Jacobs R, Willems G. Dental age estimation through volume matching of teeth imaged by cone-beam CT. Forensic Sci Int. 2006; 159 Suppl 1:S78-S83.

76. Shi H, Scarfe WC, Farman AG. Three-dimensional reconstruction of individual cervical vertebrae from cone-beam computedtomography images. Am J Orthod Dentofacial Orthop. 2007;131(3): 426-432.

77. McCrillis JM, Haskell J, Haskell BS, et al. Obstructive sleep apnea and the use of cone beam computed tomography in airway imaging: a review. Semin Orthod. 2009;15(1):63-69.

78. Ogawa T, Enciso R, Memon A, Mah JK, Clark GT. Evaluation of 3D airway imaging of obstructive sleep apnea with cone-beam computed tomography. Stud Health Technol Inform. 2005;111:365-368.

79. McCrillis J, Farman A, Scarfe W, et al. Analysis of Airway Changes using CBCT with and without Placement of a Mandibular Advancement Device. Louisville, KY: University of Louisville School of Dentistry; 2008.

80. Mathew R, Omami G, Hand A, Fellows D, Lurie A. Cone beam CT analysis of Haller cells: prevalence and clinical significance. Dentomaxillofac Radiol. 2013;42(9):20130055.

81. Hodez C, Griffaton-Taillandier C, Bensimon I. Cone-beam imaging: applications in ENT. Eur Ann Otorhinolaryngol Head Neck Dis. 2011;128(2):65-78.

82. Faccioli N, Barillari M, Guariglia S, et al. Radiation dose saving through the use of cone-beam CT in hearing-impaired patients. Radiol Med. 2009;114(8):1308-1318.
Clinical, Cosmetic and Investigational Dentistry

\section{Publish your work in this journal}

Clinical, Cosmetic and Investigational Dentistry is an international, peer-reviewed, open access, online journal focusing on the latest clinical and experimental research in dentistry with specific emphasis on cosmetic interventions. Innovative developments in dental materials, techniques and devices that improve outcomes and patient satisfaction

\section{Dovepress}

and preference will be highlighted. The manuscript management system is completely online and includes a very quick and fair peerreview system, which is all easy to use. Visit http://www.dovepress. com/testimonials.php to read real quotes from published authors. 